\title{
Urocortin expression is downregulated in human endometrial carcinoma
}

\author{
Pasquale Florio, Giulia De Falco ${ }^{1}$, Eleonora Leucci ${ }^{1}$, Michela Torricelli, Paulo B Torres, Paolo Toti ${ }^{1}$, \\ Arianna Dell'Anna, Ennio Tiso, Rosa Santopietro ${ }^{1}$, Lorenzo Leoncini ${ }^{1}$ and Felice Petraglia
}

Chair of Obstetrics and Gynaecology, Department of Paediatrics, Obstetrics and Reproductive Medicine and 'Department of Human Pathology and Oncology, University of Siena, Policlinico 'Le Scotte' Viale Bracci, 53100 Siena, Italy

(Requests for offprints should be addressed to F Petraglia; Email: petraglia@unisi.it)

\begin{abstract}
Urocortin (UCN) is a 40-amino acid neuropeptide sharing $45 \%$ sequence homology with corticotropin-releasing factor (CRF). The human endometrium expresses both UCN and CRF, and CRF/UCN receptors type-1 (CRF-R1) and -2 (CRF-R2). CRF-R1 activation inhibits cell growth and proliferation of a tumor cell line derived from the human endometrium, and the UCN signaling pathway has been implicated in tumorigenesis of several tissues. Therefore, we investigated whether UCN mRNA and peptide are expressed by human endometrial adenocarcinoma, and whether their expression changes compared to controls. Samples of well (grade $1 ; n=6$ endometrioid adenocarcinoma, of whom $n=1$ with squamous differentiation, and $n=1$ clear-cell carcinoma) and poorly differentiated (grade $3 ; n=3$ endometrioid adenocarcinoma) endometrial adenocarcinoma were collected from nine women (age range 61-79 years) enrolled at the time of diagnosis. Healthy endometrium was collected from postmenopausal women (controls; $n=13$; age range 64-78
\end{abstract}

years), who underwent hysterectomy for uterine prolapse. Immunohistochemistry was used to evaluate cellular UCN localization, with the intensity of immunostaining scored on a subjective scale. Quantitative real-time reverse transcriptase (RT)-PCR analysis was used to estimate mRNA expression changes and restriction analysis was used to confirm PCR products identity. UCN mRNA expression was significantly reduced $(P<0 \cdot 0001)$ in endometrial adenocarcinoma than in healthy controls. Immunoreactive UCN was found in luminal and glandular epithelial cells in healthy, but not in neoplastic samples. UCN mRNA and peptide expressions are decreased in endometrial adenocarcinoma. These data and the evidence that endometrial cancer expresses UCN receptors and UCN is involved in tumorigenesis of several tissues together suggest a role for UCN in endometrial tumoral cell growth and proliferation.

Journal of Endocrinology (2006) 190, 99-105

\section{Introduction}

The human endometrium expresses several peptides/proteins that are believed to participate in the paracrine signaling to other cell types during the menstrual cycle and in early pregnancy, and dysfunction in synthesis and secretion of these factors may be involved in pathological conditions, such as endometrial adenocarcinoma.

Among the locally produced brain peptides, urocortin $(\mathrm{UCN})$ is one of the most recently identified. It is a 40-amino acid neuropeptide that shares $45 \%$ sequence homology with corticotropin-releasing factor (CRF), and that, like CRF, also acts in vitro to release adrenocorticotropin from dispersed rat anterior pituitary cells (Donaldson et al. 1996). The homology with CRF is also underlined by the fact that UCN binds with different affinity to both CRF receptors type-1 (CRF-R1) and -2 (CRF-R2) (Aguilera et al. 2004).

UCN gene expression and synthesis have been reported in epithelial and stromal cells of the human endometrium, and by immunohistochemistry, the peptide has been localized in the endometrial luminal and glandular epithelial cells, and stromal cells of both proliferative and secretory endometrial phases (Florio et al. 2002). In addition, the human endometrium also expresses both CRF-R1 (Di Blasio et al. 1997) and CRF-R2 (Karteris et al. 2004), and in in vitro experimental models, the activation of the cAMP pathway induced by the binding to CRF-R1 located on endometrial stromal cells demonstrated differentiating activity, since those cells undergo decidualization (Ferrari et al. 1995). Furthermore, the activation of CRF-R1 receptor subtype, which is expressed under basal conditions by a tumor cell line derived from the human endometrium, namely adenocarcinoma Ishikawa cells, inhibits tumor cell growth, and proliferation in a dose- and time-dependent manner (Graziani et al. 2002). 
Moreover, studies in tumor models have suggested the involvement of $\mathrm{CRF} / \mathrm{UCN}$ common signaling pathways in tumorigenesis of several tissues (Tjuvajev et al. 1998, Slominski et al. 2000, Carlson et al. 2001).

In the present study, we investigated whether UCN mRNA and peptide are expressed in human endometrial adenocarcinoma, and whether their expression and localization change in comparison to healthy menopausal endometrium.

\section{Materials and Methods}

\section{Tissue collection}

Informed written consent was obtained from all patients prior to inclusion in the study, for which the local Human Investigation Committee approval was obtained. Two groups of women were studied:

(1) women with endometrial adenocarcinoma $(n=9$; age range, 61-79 years), enrolled at the time of diagnosis, who did not take any hormonal replacement therapy in their clinical history. Pathological diagnosis was done on hysterectomy specimens and, according to the criteria of the International Federation Gynecology and Obstetrics, they were classified as well (grade $1 ; n=6$ endometrioid adenocarcinoma, of whom $n=1$ with squamous differentiation, and $n=1$ clear-cell carcinoma) and poorly differentiated (grade $3 ; n=3$ endometrioid adenocarcinoma) (Table 1);

(2) postmenopausal women ( $n=13$; age range, $64-78$ years), who underwent hysterectomy for uterine prolapse (controls), that served as age-matched controls. In the clinical history of these subjects, the absence of infections or

Table 1 Intensity of urocortin (UCN) immunostaining in postmenopausal endometrium (controls) and endometrial cancer tissues scored on a subjective scale ranging from - (no staining) to ++ (maximal staining) by three independent assessors

\section{UCN immunostaining intensity}

\begin{tabular}{|c|c|c|c|c|}
\hline & $\begin{array}{l}\text { Staining } \\
\text { intensity }\end{array}$ & $\begin{array}{l}\text { Endometrial } \\
\text { cancer }\end{array}$ & $\begin{array}{l}\text { Staining } \\
\text { intensity }\end{array}$ & Grade/stage \\
\hline \multicolumn{5}{|c|}{ Controls } \\
\hline$\# 1$ & ++ & $\# 1$ & - & $1 / \mathrm{IB}$ \\
\hline \#2 & ++ & \#2 & - & $1 / \mathrm{IB}$ \\
\hline \#3 & ++ & \#3 & - & $1 / \mathrm{IC}$ \\
\hline \#4 & + & \#4 & \pm & $1 / \mathrm{IB}$ \\
\hline \#5 & ++ & $\# 5^{*}$ & \pm & $1 / \mathrm{IC}$ \\
\hline \#6 & ++ & $\# 6^{* *}$ & - & $1 / \mathrm{IC}$ \\
\hline \#7 & ++ & \#7 & \pm & $3 / \mathrm{IB}$ \\
\hline \#8 & ++ & \#8 & - & $3 / \mathrm{IB}$ \\
\hline \#9 & ++ & \#9 & - & $3 / \mathrm{IB}$ \\
\hline \#10 & ++ & & & \\
\hline \#11 & ++ & & & \\
\hline \#12 & ++ & & & \\
\hline \#13 & ++ & & & \\
\hline
\end{tabular}

*With squamous differentiation.

${ }^{* *}$ Clear-cell endometrioid adenocarcinoma. neoplastic diseases and any estrogen and/or progestin pretreatment was the exclusion criteria.

Trophoblasts collected from placentas of healthy pregnant women $(n=3)$ at term pregnancy (39 weeks of gestation) were used as positive control (Petraglia et al. 1996). The inner part of the neoplastic and healthy tissues was collected far from the myometrium, in part fixed by immersion in $10 \%$ buffered formalin for the immunohistochemistry study, and in part (about $500 \mathrm{mg}$ ) immediately submerged in a RNA stabilization reagent (RNAlater; Qiagen) for the extraction of the total RNA.

\section{$R N A$ isolation}

Total RNA was extracted from frozen tissue samples using a commercially available kit (Trizol; Invitrogen). Approximately $5 \mu$ g total RNA was subsequently treated with DNase (DNase I Set; Promega). Quantification of total RNA was performed by measuring absorbance at $\mathrm{OD}_{260}$. The quality of total RNA was controlled by running $1.5 \%$ agarose gels buffered in $89 \mathrm{mM}$ Tris, $89 \mathrm{mM}$ boric acid, and $2 \mathrm{mM}$ EDTA $(\mathrm{pH} 8 \cdot 3)$ and assessed as acceptable if strong and intact 28S rRNA and 18S rRNA bands were visible under u.v. light after staining with ethidium bromide. No bands of genomic DNA were observed in agarose gels after DNase treatment. cDNA synthesis from total RNA $(1 \mu \mathrm{g})$ was carried out in a reaction volume of $20 \mu \mathrm{l}$ containing $50 \mathrm{mM}$ Tris- $\mathrm{HCl}(\mathrm{pH} 8 \cdot 3)$, $75 \mathrm{mM} \mathrm{KCl}, 3 \mathrm{mM} \mathrm{MgCl}, 10 \mathrm{mM}$ dithiothreitol, $5 \mu \mathrm{M}$ random hexamer primer, $2 \cdot 7 \mathrm{mM}$ deoxynucleoside triphosphate (all reagents obtained from Invitrogen) and moloney murine leukemia virus retrotranscriptase (Ambion, Celbio $\mathrm{SpA}$, Pero, Italy) in the presence of RNAsin (Ambion). RNA was initially denatured at $85^{\circ} \mathrm{C}$ for $5 \mathrm{~min}$. The reaction mixture was then added and reverse transcription was performed at $42{ }^{\circ} \mathrm{C}$ for $90 \mathrm{~min}$. The reaction was stopped by denaturing the enzyme at $85^{\circ} \mathrm{C}$ for $15 \mathrm{~min}$. The cDNA was immediately subjected to qualitative PCR and quantitative real-time reverse transcriptase (RT)-PCR. For each RNA sample, a parallel reaction tube was prepared as described earlier, but without reverse transcriptase (RTnegative control).

\section{Real-time quantitative RT-PCR analysis}

To quantify mRNA expression of UCN, real-time quantitative RT-PCR was performed using SYBR Green I dye kit (based on a uniquely modified Thermus brockianus (Tbr) DNA polymerase) according to the manufacturer's instructions (Finnzymes, Espoo, Finland), through a DNA Engine Opticon 2 (MJ research, BioRad). All samples were run in duplicates on 96-well optical PCR plates (Applied Biosystems, Weiterstadt, Germany). Standard RNA preparations were included in every RT-PCR run. The mastermix used for real-time PCR was the Dynamo SYBR Green (Finnzymes) that allows reproducible detection of 
low copy number templates. The advantage provided by this mix is to offer more efficient amplification coupled with increased polymerase processivity results in earlier $\mathrm{C}(\mathrm{t}) \mathrm{s}$ and shorter overall quantitative PCR times.

UCN was normalized to hypoxanthine phosphoribosyltransferase (HPRT, used as a housekeeping gene (Vigano et al. 2002)). The specific primers used to amplify cDNA fragments corresponding to UCN (Gene bank access no. NM003353) and HPRT (Gene bank access no. NM000194) were: 5'-GCTTGCTGGTGAAAAGGACC-3' (sense); 5'-CTTG CCCACCGAGTCGAAT-3' (antisense) for UCN (expected size, $145 \mathrm{bp}$ ); and $5^{\prime}$-TGAAGCTGCAGACACTCAGG- ${ }^{\prime}$ (sense); and 5'-CTCTCCCAACACCATCACCT- $3^{\prime}$ (antisense) for HPRT (included intron size, 270; expected size, $99 \mathrm{bp}$ ). Computer analysis performed to compare the synthesized oligomers with the human sequences in the gene database of the National Center Biotechnology (NCBI), using BLAST (Altschul et al. 1997), revealed no significant homology among all others genes. Sequence homology among the different oligomers used in the present study was also avoided, excluding possible cross reactions.

To amplify the housekeeping gene HPRT, the same RNA of each sample was used and all the experiments were performed in duplicate. After an initial denaturation for $1 \mathrm{~min}$ at $95^{\circ} \mathrm{C}$, denaturation at the subsequent $40-50$ cycles was performed for $15 \mathrm{~s}$ at $95^{\circ} \mathrm{C}$, followed by $15 \mathrm{~s}$ primer annealing at $60^{\circ} \mathrm{C}$ for HPRT and $58^{\circ} \mathrm{C}$ for UCN respectively with a final extension at $72{ }^{\circ} \mathrm{C}$ for $15 \mathrm{~s}$ (for both). The $\Delta \Delta \mathrm{C}_{\mathrm{T}}$ method (Livak and Schmittgen 2001) was applied as a comparative method of quantification.

The specificity of the amplified fragment was demonstrated by the melting curve, where a single peak was observed for each sample amplified with UCN primers. Any other nonspecific product, such as primer-dimers, is easily detected in this step. The presence of a single peak is a demonstration that no unspecific amplicon has been produced during the amplification.

\section{Assessment of PCR product}

The PCR product identity was confirmed by restriction analysis. In brief, the PCR products were extracted with phenol:chloroform and precipitated with ethanol. The amplified fragment was digested with AVAII (Sigma) following the manufacturer's suggested conditions. The products were separated by $12 \%$ PAGE, visualized by ethidium bromide staining under u.v. light, using PUC Mix marker 8 (M-Medical, Milan, Italy), and photographed.

\section{Immunohistochemistry}

To evaluate the localization of UCN, immunohistochemistry was carried out on $5 \mu \mathrm{m}$ thick sections, obtained from paraffin-embedded samples, mounted on electrostatically charged slides, and dried overnight at $37^{\circ} \mathrm{C}$. Sections were de-waxed, rehydrated, and washed in Tris-buffered saline
(TBS; $20 \mathrm{mM}$ Tris- $\mathrm{HCl}, 150 \mathrm{mM} \mathrm{NaCl}(\mathrm{pH} 7 \cdot 6)$ ). Tissue solutions were heated in a microwave oven 2 times for $5 \mathrm{~min}$ at $750 \mathrm{~W}$ and rinsed in $3 \% \mathrm{H}_{2} \mathrm{O}_{2}$ to block endogenous peroxidase. Slides were incubated overnight at room temperature with primary antibody.

The antiserum used for UCN was a rabbit anti-human polyclonal antibody diluted 1:1000, provided by Professor W. Vale (Salk Institute, La Jolla, CA, USA). The reactions were developed by successive incubations with anti-rabbit immunoglobins labeled with biotin, the avidin-biotin peroxidase complex (Vector Lab, Burlingame, CA, USA)

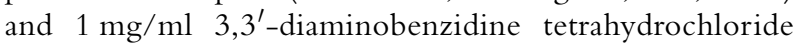
(Sigma) as chromogen substrate, in TBS containing $0 \cdot 3 \%$ $\mathrm{H}_{2} \mathrm{O}_{2}$. Harris hematoxylin was used for nuclear counterstaining. A positive reaction was characterized by the presence of granular brown staining in the cytoplasm.

For each case, a negative control was obtained using the antibody preadsorbed with the corresponding peptide at the concentration of $20 \mu \mathrm{g} / \mathrm{ml}$ diluted antibody.

\section{Assessment of staining}

The individual intensity of immunostaining of tissue section was scored on a subjective scale, i.e. 0 (no staining), \pm focal weak staining, + weak diffuse staining, ++ intense diffuse staining, by three independent assessors.

\section{Statistical analysis}

After confirming a normal distribution, mRNA data were summarized as means \pm s.E.M. Between-group differences were evaluated by using the unpaired $t$-test, and statistical significance assumed when $P<0 \cdot 05$.

\section{Results}

\section{Expression of UCN $m R N A$}

Total RNA extracted from endometrium was analyzed by RT-PCR. A band corresponding in size to UCN product (145 bp) was obtained and no amplified fragment caused by DNA contamination was detected in any experiment (-RT). The average Ct of UCN in tumor samples was 26.42 vs 21.68 of HPRT. Normal tissue showed an average value of 26.56 for UCN vs 22.21 for HPRT. A representative result of this RT-PCR is shown in Fig. 1A. The identity of UCN PCR product was then confirmed by restriction analysis with AvaII. As shown in Fig. 1B, the $145 \mathrm{bp} \mathrm{PCR} \mathrm{fragment}$ contained an AvaII site yielding products of expected size in all the samples examined.

When evaluated by quantitative real-time RT-PCR, the expression of UCN mRNA in the endometrial carcinoma was significantly $(P<0 \cdot 0001)$ lower than in healthy postmenopausal endometrium (Fig. 2). 
A

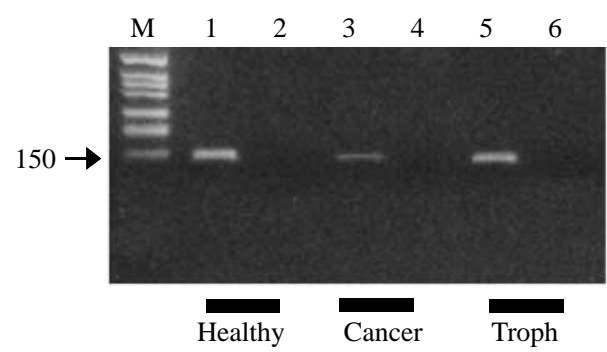

B

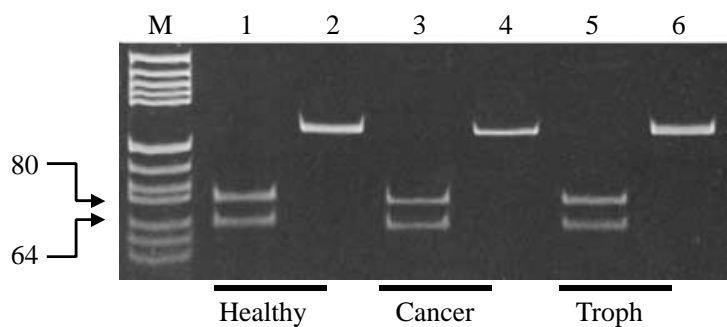

Figure 1 Representative results of the RT-PCR analysis of UCN (A) mRNA in healthy endometrium and endometrial cancer. Lane 1, postmenopausal healthy endometrium (Healthy); lane 3, endometrial adenocarcinoma (Cancer); lane 5, trophoblasts (Troph, positive control). Lanes 2, 4, and 6, blanks. Blanks for each reaction consisted of amplifications performed in absence of reverse transcriptase enzyme. $m$, molecular weight (marker VIII; Roche). (B) UCN PCR product verification by restriction analysis. Fragments digested with Avall and undigested, of healthy endometrium (Healthy, lanes 1 and 2); endometrial adenocarcinoma (Cancer, lanes 3 and 4); trophoblasts (Troph, lanes 5 and 6), were analyzed by PAGE. Predicted sizes of fragments are 61 and $84 \mathrm{bp}$. The size of molecular weight markers $(M ; b p)$ is indicated.

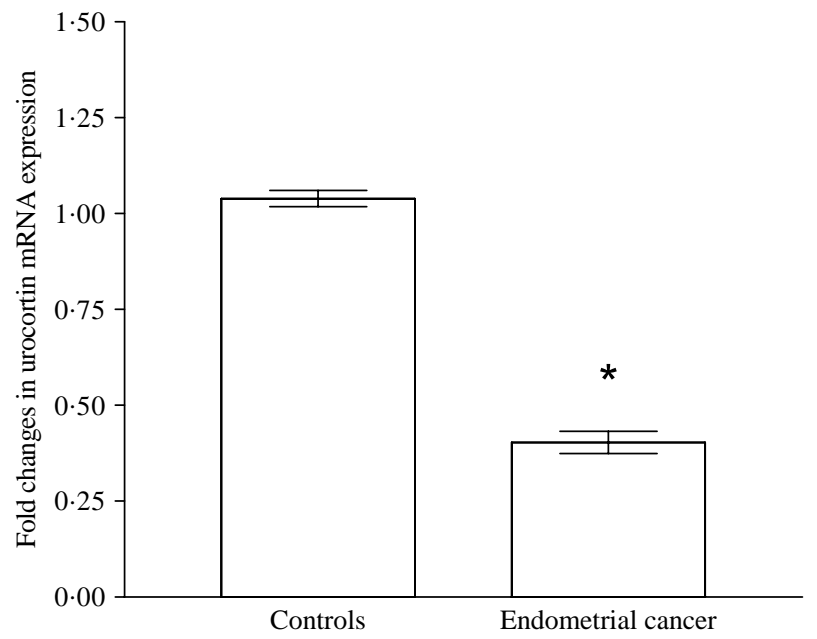

Figure 2 Expression of UCN mRNA in samples of healthy endometrium and endometrial cancer. Results of quantitative realtime RT-PCR demonstrate that UCN mRNA expression is significantly reduced in endometrial adenocarcinoma. ${ }^{*} P<0 \cdot 0001$, unpaired $t$-test.

\section{Localization of UCN peptide}

In normal postmenopausal endometrium, luminal and glandular (Fig. 3A and B) epithelial cells were strongly and consistently immunoreactive for UCN. Vascular endothelial cells were also stained, while stromal cells showed weak or absent immunostaining (Fig. 3A and B).

In samples of endometrial adenocarcinoma obtained from postmenopausal women, the staining for UCN was very weak or absent both in epithelial and stromal cells when compared to healthy counterparts entrapped in the same slide (Fig. 3B). This result was constantly observed in all the different samples of endometrial adenocarcinoma evaluated, independent of the different grade of differentiation (Fig. 3B, grade 1 endometrioid adenocarcinoma; $\mathrm{C}$, grade 3 poorly differentiated endometrioid adenocarcinoma; $\mathrm{D}$, clear cell variant; $\mathrm{E}$, grade 2 endometrioid adenocarcinoma; F, grade 1 endometrioid adenocarcinoma). Vessel walls showed positive UCN immunostaining in samples of healthy (Fig. 3A) and neoplastic (Fig. 3C-E) endometrium. When compared to healthy samples, UCN staining intensity was significantly lower $(P<0 \cdot 0001$; data not shown).

\section{Discussion}

In the present study, we first demonstrated that human postmenopausal endometrium expresses UCN mRNA and peptide, and that UCN is mainly localized in epithelial (both luminal and glandular) and endothelial cells, thus resembling, only in part, the localization previously reported in fertile women. Indeed, by immunohistochemistry, UCN was depicted both in endometrial luminal and glandular epithelial cells, and moderate immunoreactivity was found in stromal cells of both proliferative and secretory phase specimens (Florio et al. 2002). Taken together, these findings lead us to suggest that in the human endometrium, UCN expression may be under the influence of ovarian steroid hormones that are low in postmenopause - and may be involved in maintaining the local expression of UCN in the human endometrium (Petraglia et al. 1996, Florio et al. 2002).

The second result of the present study is that UCN expression is decreased in endometrial cancer, opening a new question on the role played by the UCN pathway in endometrial tumorigenesis. In this regard, no in vitro data are available on local UCN effects (Florio et al. 2004). However, the endometrial expression and distribution of UCN (Florio et al. 2002), the high homology in sequence and biological activity with CRF (Donaldson et al. 1996), together with the high affinity of the peptide for CRF receptors (Aguilera $e t$ al. 2004) lead us to suggest that UCN may be involved in several aspects of endometrial physiology, as already shown for CRF (Florio et al. 2003). Indeed, CRF induces differentiation of human endometrial cells (Ferrari et al. 1995), and such process follows the activation of the cAMP pathway (Ferrari et al. 1995, Graziani et al. 2002). Therefore, taken collectively, this evidence indicate that activation of 

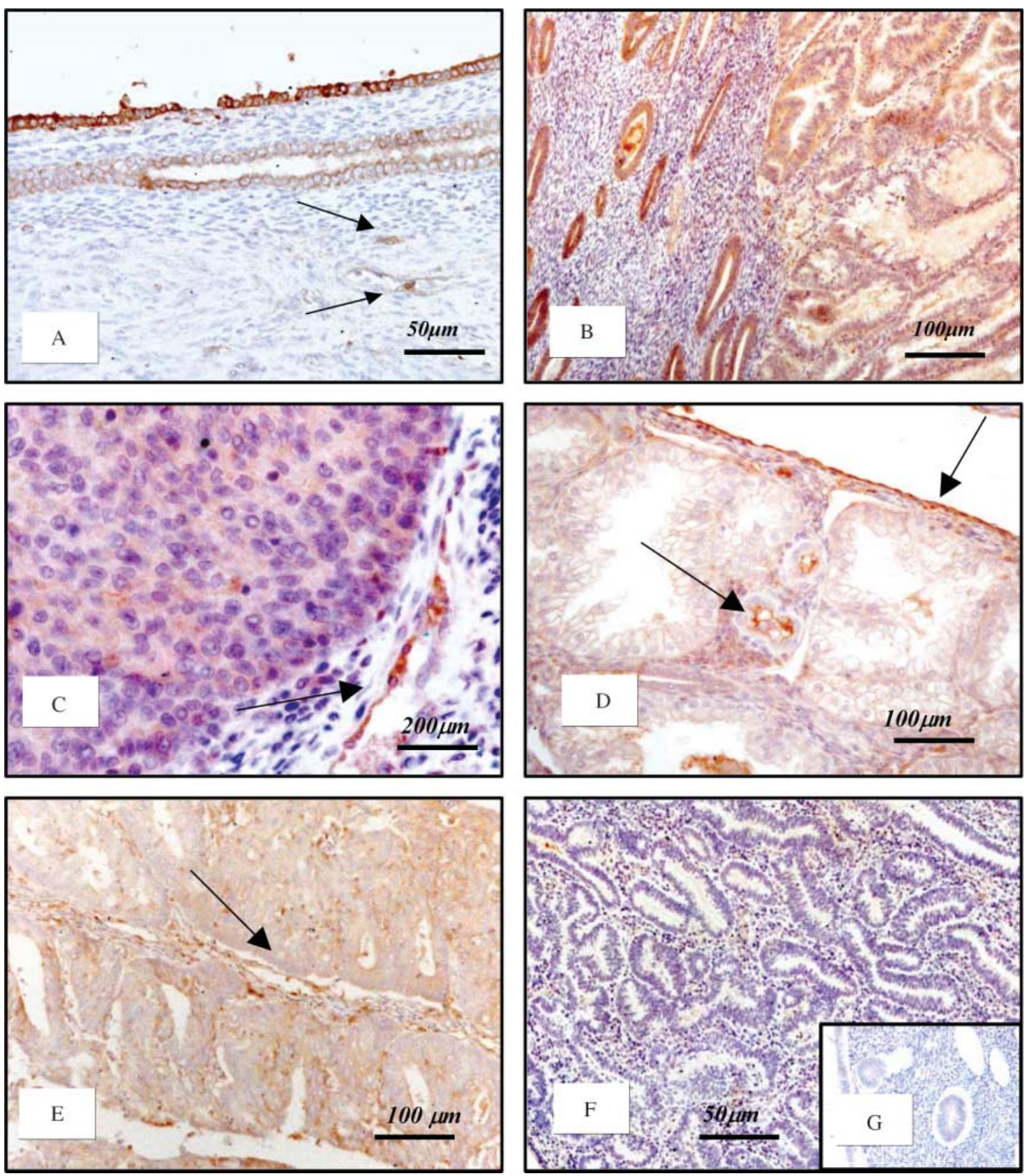

Figure 3 Localization of $U C N$ by immunohistochemistry. In postmenopausal healthy endometrium (A), UCN staining was observed in vessels (arrows) and in both luminal and glandular endometrial cells. (B) Well-differentiated endometrioid adenocarcinoma grade 1 (right side of the section) growing on postmenopausal endometrium (left side of the section). Non-neoplastic endometrial glands were immunostained, but the immunostaining was weak or absent in neoplastic cells. (C) Grade 3 poorly differentiated endometrioid adenocarcinoma; (D) clear-cell variant; (E) grade 2 endometrioid adenocarcinoma, and (F) grade 2 endometrioid adenocarcinoma. UCN immunoreactivity was observed only in vessel walls (arrows). (G) Negative control.

CRF receptors likely contributes to the control of normal endometrial function under physiological conditions.

Neoplastic cells derived from endometrial cancers maintain the expression of CRF receptors as well as normal signal transduction mechanisms (Graziani et al. 2002). Furthermore, there is also evidence that the activation of CRF/UCN receptor pathway has growth inhibitory effects on endometrial adenocarcinoma cells in a dose- and time-dependent manner, and that such growth inhibition is mediated by the activation of cAMP-protein kinase A pathway that, in turn, may induce 
differentiation of endometrial neoplastic cells (Graziani et al. 2002). Recently, it was shown that CRF counteracts endometrial tumoral cell proliferation, and that its effect is mediated through the type-1 receptor (Graziani et al. 2006). However, the role of UCN in the control of neoplastic disease has been scarcely investigated. However, recent evidence has shown that UCN inhibits proliferation of melanoma cells in vitro, by activation of CRF-R1 and subsequent altered intracellular $\mathrm{Ca}^{2++}$ signaling (Carlson et al. 2001). Furthermore, UCN also inhibits proliferation of human keratinocytes by stimulating the cAMP pathway (Slominski et al. 2000). Finally, there is evidence for an anti-proliferative effect of CRF-R1 activation in W256 rat mammary cancer cells, coupled with a differentiation-inducing effect (Tjuvajev et al. 1998). This evidence, and the findings of reduced UCN expression in endometrial adenocarcinoma, allow us to suggest that in endometrial cancer, the reduced expression of UCN may lead to the lack of a UCN-mediated inhibition of cell proliferation, and therefore may contribute to endometrial tumor progression. In addition, the data on UCN immunostaining in vascular vessels, the findings on the role of UCN in endothelial cell functions (Coste et al. 2000, Huang et al. 2002), and the expression of CRF-Rs on human endothelial cells (Simoncini et al. 1999, Sanz et al. 2002) together suggest a role for this neuropeptide in vascular proliferation and angiogenesis. Indeed, activation of CRF-R2 results in a tonic suppressor of vascularization, and that mechanism has been postulated in the modulation of angiogenesis in cancer (Bale et al. 2002).

In conclusion, mRNA and peptide UCN expressions are decreased in endometrial adenocarcinoma; the failure of a final common pathway, through the activation of different intracellular messengers, involved in the inhibition of cell growth and proliferation may be pivotal in the endometrial tumor progression. However, the family of UCN also comprises UCN II and UCN III that share high homologies in UCN amino acid sequences, and specifically bind to CRFR2 (Florio et al. 2004). Since UCN binds with different affinity to both CRF-R1 and CRF-R2 (Aguilera et al. 2004), studies on the expression of UCN II, UCN III, and CRF-R2 in endometrial cancer, and effect of CRF-R2 antagonists on the proliferation and differentiation of the endometrial carcinoma cell lines would expand our knowledge on the net role played by UCNs in endometrial tumorigenesis. Therefore, the presence of $\mathrm{CRF} / \mathrm{UCN}$ receptors in endometrial cancer and the local lack of UCN expression may be propitious for certain clinical applications, i.e., as a target for long-term UCN therapy.

\section{Acknowledgements}

The authors declare that there is no conflict of interest that would prejudice the impartiality of this scientific work.

\section{References}

Aguilera G, Nikodemova M, Wynn PC \& Catt KJ 2004 Corticotropin releasing hormone receptors: two decades later. Peptides 25 319-329.

Altschul SF, Madden TL, Schaffer AA, Zhang J, Zhang Z \& Miller W 1997 Gapped BLAST and PSI-BLAST: a new generation of protein database search programs. Nucleic Acids Research 25 3389-3402.

Bale TL, Giordano FJ, Hickey RP, Huang Y, Nath AK, Peterson KL, Vale WW \& Lee KF 2002 Corticotropin-releasing factor receptor 2 is a tonic suppressor of vascularization. PNAS 99 7734-7739.

Carlson KW, Nawy SS, Wei ET, Sadee W, Filov VA, Rezsova VV, Slominski A \& Quillan MJ 2001 Inhibition of mouse melanoma cell proliferation by corticotrophin-releasing hormone and its analogs. Anticancer Research 21 1173-1179.

Coste SC, Kesterson RA, Heldwein KA, Stevens SL, Heard AD, Hollis JH, Murray SE, Hill JK, Pantely GA, Hohimer AR et al. 2000 Abnormal adaptations to stress and impaired cardiovascular function in mice lacking corticotropin-releasing hormone receptor-2. Nature Genetics 24 403-409.

Di Blasio AM, Giraldi FP, Vigano P, Petraglia F, Vignali M \& Cavagnini F 1997 Expression of corticotropin-releasing hormone and its R1 receptor in human endometrial stromal cells. Journal of Clinical Endocrinology and Metabolism 82 1594-1597.

Donaldson CJ, Sutton SW, Perrin MH, Corrigan AZ, Lewis KA, Rivier JE, Vaughan JM \& Vale WW 1996 Cloning and characterization of human urocortin. Endocrinology 137 2167-2170.

Ferrari A, Petraglia F \& Gurpide E 1995 Corticotropin releasing factor decidualizes human endometrial stromal cells in vitro, Interaction with progestin. Journal of Steroid Biochemistry and Molecular Biology $\mathbf{5 4}$ 251-255.

Florio P, Arcuri F, Ciarmela P, Runci Y, Romagnoli R, Cintorino M, Di Blasio AM \& Petraglia F 2002 Identification of urocortin mRNA and peptide in the human endometrium. Journal of Endocrinology 173 R9-R14.

Florio P, Rossi M, Sigurdardottir M, Ciarmela P, Luisi S, Vigano P, Grasso D, Fiore G, Cobellis L, Di Blasio AM et al. 2003 Paracrine regulation of endometrial function: interaction between progesterone and corticotropinreleasing factor (CRF) and activin A. Steroids $\mathbf{6 8} 801-807$.

Florio P, Vale W \& Petraglia F 2004 Urocortins in human reproduction. Peptides 25 1751-1757.

Graziani G, Tentori L, Portarena I, Barbarino M, Tringali G, Pozzoli G \& Navarra P 2002 CRH inhibits cell growth of human endometrial adenocarcinoma cells via CRH-receptor 1-mediated activation of cAMPPKA pathway. Endocrinology 143 807-813.

Graziani G, Ferrandina G, Pozzoli G, Vergati M, Muzi A, Legge F, Tentori L, Scambia G \& Navarra P 2006 Corticotropin-releasing hormone receptor-1 in human endometrial cancer. Oncology Reports 15 375-379.

Huang Y, Chan FL, Lau CW, Tsang SY, He GW, Chen ZY \& Yao X 2002 Urocortin-induced endothelium-dependent relaxation of rat coronary artery: role of nitric oxide and $\mathrm{K}+$ channels. British Journal of Pharmacology 135 1467-1476.

Karteris E, Papadopoulou N, Grammatopoulos DK \& Hillhouse EW 2004 Expression and signalling characteristics of the corticotrophin-releasing hormone receptors during the implantation phase in the human endometrium. Journal of Molecular Endocrinology 32 21-32.

Livak KJ \& Schmittgen TD 2001 Analysis of relative gene expression data using real-time quantitative PCR and the 2(-delta delta $\mathrm{C}(\mathrm{T})$ ) method. Methods 25 402-408.

Petraglia F, Florio P, Gallo R, Simoncini T, Saviozzi M, Di Blasio AM, Vaughan J \& Vale W 1996 Human placenta and fetal membranes express human urocortin mRNA and peptide. Journal of Clinical Endocrinology and Metabolism 81 3807-3810.

Sanz E, Monge L, Fernandez N, Martinez MA, Martinez-Leon JB, Dieguez G \& Garcia-Villalon AL 2002 Relaxation by urocortin of human saphenous veins. British Journal of Pharmacology 136 90-94. 
Simoncini T, Apa R, Reis FM, Miceli F, Stomati M, Driul L, Lanzone A, Genazzani AR \& Petraglia F 1999 Human umbilical vein endothelial cells: a new source and potential target for corticotropin-releasing factor. Journal of Clinical Endocrinology and Metabolism 84 2802-2806.

Slominski A, Roloff B, Zbytek B, Wei ET, Fechner K, Curry J \& Wortsman J 2000 Corticotropin-releasing hormone and related peptides can act as bioregulatory factors in human keratinocytes. In Vitro Cellular and Developmental Biology-Animal 36 211-216.

Tjuvajev J, Kolesnikov Y, Joshi R, Sherinski J, Koutcher L, Zhou Y, Matei C, Koutcher J, Kreek MJ \& Blasberg R 1998 Anti-neoplastic properties of human corticotropin releasing factor: involvement of the nitric oxide pathway. In Vivo 12 1-10.
Vigano P, Somigliana E, Mangioni S, Vignali M, Vignali M \& Di Blasio AM 2002 Expression of interleukin-10 and its receptor is up-regulated in early pregnant versus cycling human endometrium. Journal of Clinical Endocrinology and Metabolism 87 5730-5736.

Received 4 January 2006

Received in final form 23 March 2006

Accepted 7 April 2006

Made available online as an Accepted Preprint 3 May 2006 